\title{
APPLYING GRAPHIC DESIGN PRINCIPLES ON TEA PACKAGING
}

\author{
Dorotea Kovačević (iD, Maja Brozović (iD), Dubravko Banić \\ University of Zagreb, Faculty of Graphic Arts, Zagreb, Croatia
}

\begin{abstract}
The aesthetic aspect of product packaging is a well-known factor in attracting consumers' attention. One of the most common ways in achieving the aesthetic appearance of the packaging is applying graphic design principles. The purpose of the study was to explore how people perceive the attractiveness of tea packaging with different levels of graphic design principles applied. The graphic design principles applied on the packaging were: contrast, dominance, alignment, symmetry, consistency and colour harmony. The manipulation of these principles resulted in three different packaging samples that were tested: aesthetic packaging, partially-aesthetic packaging and non-aesthetic packaging. The participants' tasks were to rate the attractiveness of each of the packaging samples and to select the one which they would like to buy. The statistical analysis showed that the results of both tests (rating and choice task) were consistent, indicating that the aesthetic packaging was appreciated the most, followed by the partially-aesthetic packaging and the non-aesthetic packaging. These results were the same even when taking into account whether the beauty of the packaging was important to the participants or not. The findings support the idea of using graphic design principles in packaging design whenever applicable.
\end{abstract}

Keywords: graphic design, packaging, attractiveness, tea

\section{INTRODUCTION}

The role of product packaging is multifaceted. Not only it protects the product, but also transmits the information about the product through its visual elements. The graphic design of these visual elements is one of the most powerful tools for creating the aesthetic aspect of product packaging and attracting consumers' attention during the buying process. The aesthetic packaging makes products visually appealing, which creates a potential for eliciting positive impressions on consumers. This was confirmed by many studies during the last decade (Honea and Horsky, 2012; Van der Laan et al, 2012; Westerman et al, 2013). Furthermore, it was found that people tend to choose aesthetic packaging rather than standardized packaging (Reimann et al, 2010).

One of the most common ways in achieving the aesthetic appearance of packaging is applying graphic design principles while creating the packaging. The most popular design principles are Gestalt laws for organizing visual form and space (Puhalla, 2011), which professional designers apply not only on packaging, but also on other print media as well as on screen design (Chang et al, 2002). Beside the Gestalt laws, graphic designers are trained to apply other design principles (of which some overlap with Gestalt laws or originate in them), such as unity, proportion, dominance (Pham, 1999), contrast (Williams and Stimatz, 2005; Chevalier and Kicka, 2006), alignment (Williams, 2014), symmetry (Ngo et al, 2000) and colour harmony (Puhalla, 2011).

Few of the design principles were included in previous studies that investigated the role of visual design in different experimental conditions. For example, Tomko and Zaitseva (2009) analyzed the requirements for good visual design of e-learning systems and pointed out unity as one of the criteria for their evaluation. High level of unity was also perceived as attractive to younger participants in the case of digital learning games (Javora et al, 2019). The principle of colour contrast was especially interesting to researchers. Silvennoinen et al (2014) reported about the importance of colour contrast for effective visual usability. Ling and Van Schaik (2002) investigated the use of colour on web pages and found that higher colour contrasts were rated more favorably by the participants. Web pages were also tested by Lazard and Mackert (2014), who found that principles of design complexity influenced the participants' first impressions and their evaluation of the pages' beauty and utility. However, none of the mentioned studies assessed the effect of design principles in packaging design.

Thus, our aim was to explore how people perceive the attractiveness of product packaging with different levels of applied graphic design principles. Additionally, we wanted to investigate the effect of design principles on people's choices and find out whether their evaluation of product packaging is affected by their attitude toward the importance of aesthetics in their buying decisions. 


\section{METHODOLOGY}

36 participants ( 22 women and 14 men) volunteered for the experiment. All of them were tea users. The age of the participants ranged from 24 to $83(\mathrm{M}=39.781$, SD = 13.01). All had normal or corrected-tonormal vision. The experiment was conducted in a laboratory setting of the University of Zagreb. The stimuli were presented on-screen, using a Lenovo computer display L1900pA. The resolution was set to $1280 \times 1024$ pixels. The size of each packaging stimulus (i.e. the front side of a packaging box) was $83 \times$ $125 \mathrm{~mm}$. Due to the nature of our research question and the importance of stimuli's visual appearance, a special effort was put on the stimuli's design.

As was the case in many previous studies (Germelmann and Held, 2014; Vladić et al, 2016; Kovačević et al, 2019), tea packaging was selected as stimuli. The stimuli were created according to aesthetic and ergonomic principles commonly used in graphic design projects. For the purpose of this study, we used only the principles which can be easily manipulated on the type of packaging which was selected as the object of the investigation. The graphic design principles used as variables were: colour harmony, symmetry, alignment, dominance, contrast and consistency. Manipulation of these principles resulted in three different packaging samples used as stimuli that were tested: an aesthetic packaging, a partiallyaesthetic packaging and a non-aesthetic packaging (Figure 1).

On the aesthetic packaging, we use all the above mentioned principles. We applied a harmonic colour palette as suggested by Puhalla (2011). The arrangement of visual elements was based on symmetrical composition since symmetry was pointed out as one of the useful graphic design principles in previous works (Ngo et al, 2000; Lidwell et al, 2010). According to Williams's suggestion (Williams, 2014), the elements were aligned where possible. Furthermore, we created dominance, one of the basic principles suggested by Pham (1999) by enlarging the illustration. We also used good contrast (Williams and Stimatz, 2005; Chevalier and Kicka, 2006) between the text and its background. The consistency was achieved through the use of the same font family. The exception was the tea name, which was formed to fit the illustration style.

On the partially-aesthetic packaging we kept the symmetrical composition, but the application of other principles was changed. We used a less harmonic colour palette, poorer contrast and the elements were aligned to a lesser extent. The design did not include any extremely dominant visual element. The consistency was degraded by using four different fonts.

On the non-aesthetic packaging, none of the graphic design principles was applied. The colours were nonharmonic and the composition was unbalanced. There was no alignment and no clear dominance. The contrast between the text and its background was extremely poor. The consistency was even more degraded than in the previous packaging by using five different fonts and styles.

The participants took part in the experiment one at a time. They were asked to view the packaging on the screen in the similar way as they would during their usual shopping activities. Their task was to rate the attractiveness of the packaging, one by one, using a 5-point Likert scale. After that, they had a choice task in which they were asked to select among the three examples of packaging, the one which they would most likely buy in a store. Both tasks (the evaluation of attractiveness and the choice task) had no time limit. After completing the tasks participants answered to the question "Is the beauty of the packaging important to you when you buy tea?".

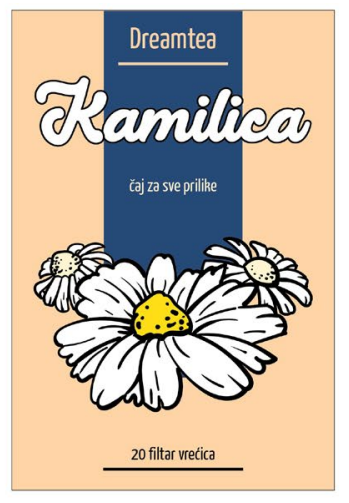

Aesthetic packaging

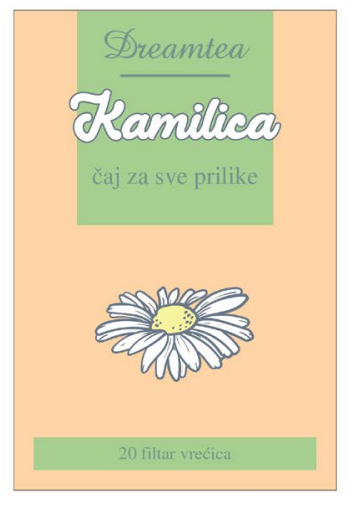

Partially-aesthetic packaging

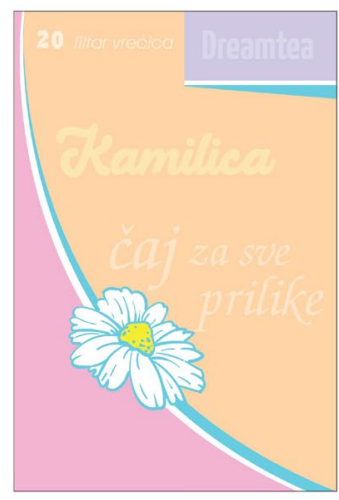

Non-aesthetic packaging

Figure 1: Packaging samples used in our experiment 


\section{RESULTS}

To examine whether aesthetics influences the perception of the attractiveness of the packaging, a repeated measures analysis of variance was used. There was a significant effect of the aesthetic aspect of the packaging, $F(2,70)=50.60, p<0.001$, suggesting that the packaging with different levels of applied graphic design principles was differently evaluated by the participants. Additional post hoc analyses with Bonferroni correction showed significant differences between all the packaging pairs. The aesthetic packaging was more attractive than the partially-aesthetic packaging, $t(35)=3.98, p<0.001$ and the nonaesthetic packaging $t(35)=9.43, p<0.001$. Furthermore, the partially-aesthetic packaging was more attractive than the non-aesthetic packaging $\mathrm{t}(35)=6.35, \mathrm{p}<0.001$. The aesthetic packaging was the best rated $(M=4.11, S D=0.85)$, followed by the partially-aesthetic packaging $(M=3.31, S D=0.98)$, and the non-aesthetic packaging $(M=2.06, S D=1.12)$. Additionally, there were no significant differences between the groups when taking into account whether the beauty of packaging was important for the participants or not; $\mathrm{t}(34)=0.38, \mathrm{p}=0.71$ in the aesthetic packaging condition, $\mathrm{t}(34)=0.15, \mathrm{p}=0.18$ in the partially-aesthetic packaging condition and $\mathrm{t}(34)=0.74, \mathrm{p}=0.61$ in the non-aesthetic packaging condition. Figure 2 illustrates these results.

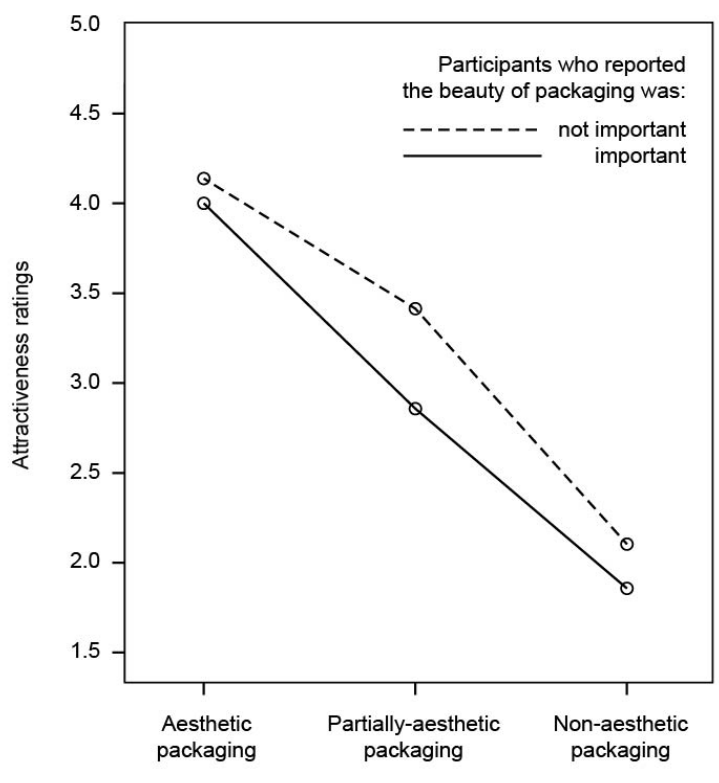

Figure 2: Attractiveness ratings across the conditions

Cochran's $\mathrm{Q}$ test was used to examine the influence of aesthetics on the frequency of participants' choices in the choice task. The results showed a significant difference in participants' selection of packaging, $\chi^{2}(2)=30.17, p<0.001$. Post hoc analyses were done by McNemar's tests with Bonferroni correction. The aesthetic packaging was chosen by the biggest number of the participants (75\%). Significantly fewer participants chose the partially-aesthetic packaging $(22.2 \%), p<0.01$ and the nonaesthetic packaging (2.8\%), $p<0.001$. However, there was no significant difference in the participants' choices between the partially-aesthetic packaging and the non-aesthetic packaging, $p=0.039$.

\section{DISCUSSION}

Our study showed that aesthetics influences consumers' perception of the packaging and their choices. When choosing between three options, the majority of the participants selected the packaging with the highest level of aesthetics (i.e. with inclusion of all the graphic design principles). The aesthetic value is an attribute which has been shown to influence people's choices (Van der Laan et al, 2012). This is in line with a research of Reimann et al (2010) who used a choice task in the investigation of aesthetic packaging for food products. The examples of packaging that were richer in their visual appeal were chosen over well-known brands, despite higher prices. The results of another task in our study (the evaluation of packaging) also confirm the participants' inclination to aesthetically appealing packaging. The aesthetic packaging was the best rated one, followed by the partially-aesthetic packaging and the non-aesthetic 
packaging. This was expected since previous research showed that package visual design can alter consumers' perception and evaluation of a product (Underwood and Klein, 2002). The effectiveness of the design of the aesthetic packaging in our experiment was based on the graphic design principles whose power was also demonstrated in several other studies. For example, Bigoin-Gagnan and LacosteBadie (2018) used the front of product packaging as stimuli in their research which revealed that aesthetic evaluation was higher when elements on the packaging were symmetrically rather than asymmetrically composed. Harmony was also found to have an influence on people's perception of attractiveness in the case of marketing visuals (Nickel et al, 2016; Nickel et al, 2020). Finally, of all the principles used in our study, the most prominent was the contrast. This attribute was found to be an effective tool for evoking the participants' positive reactions to visual content (Ling and Van Schaik, 2002), so probably this was also the case in our study. It is likely that the poor contrast in our non-aesthetic packaging sample led to a low level of visual appeal and to reduced font legibility. As demonstrated in a study focused on tea beverage packages (Mukai and Miyazaki, 2016), font legibility may play a role in rating the overall aesthetic impression of the packaging.

Another interesting finding was that positive effect of design principles on attractiveness remained the same even when taking into account whether the beauty of packaging was important for the participants or not. This suggests that people prefer aesthetic product packaging even if they do not see packaging visual appeal as an important factor in making their buying decisions. Our overall results confirm previous research on packaging design which demonstrated that visual aesthetics of food product packaging influences the consumers' evaluation of a product (Honea and Horsky, 2012). In most cases, the aesthetic packaging creates an impression of good quality in a product (Orth et al, 2010; Westerman et al, 2013). It seems that the packaging samples used in our study were not an exception.

\section{CONCLUSIONS}

The results of our study demonstrated how useful the application of design principles can be in the area of tea packaging design. If a designer applies graphic design principles intentionally, there is a greater possibility for creating an aesthetic visual design. Consumers perceive a highly aesthetic packaging as attractive and preferable when making buying choices. In line with these results, it can be concluded that the aesthetic component of the packaging is an important part of successful marketing, even with a low involvement product such as tea. Future studies should examine the perception of other low involvement products in relation to packaging aesthetics. They should also include more graphic design principles and use more objective measures of participants' responses, such as eye-tracking data.

\section{REFERENCES}

[1] Bigoin-Gagnan, A., Lacoste-Badie, S.: "Symmetry influences packaging aesthetic evaluation and purchase intention", International Journal of Retail and Distribution Management 46, 1026-1040, 2018. doi: 10.1108/IJRDM-06-2017-0123.

[2] Chang, D., Dooley, L., Tuovinen, J.E.: "Gestalt theory in visual screen design - A new look at an old subject", $7^{\text {th }}$ World Conference on Computers in Education 2002, (WCCE, 2002), pages 5-12.

[3] Chevalier, A., Kicka, M: "Web designers and web users: Influence of the ergonomic quality of the web site on the information search", International Journal of Human Computer Studies 64, 1031 1048, 2006. doi: 10.1016/j.ijhcs.2006.06.002.

[4] Germelmann, C.C., Held, J.: "Deceived or not deceived: How food consumers perceive deception", (MN: Association for Consumer Research, 2014.), pages 313-317.

[5] Honea, H., Horsky, S.: "The power of plain: Intensifying product experience with neutral aesthetic context", Marketing Letters 23, 223-235, 2012. doi: 10.1007/s11002-011-9149-y.

[6] Javora, O., Hannemann, T., Starkova, T., Volna, K., Brom, C.: "Children like it more but don't learn more: Effects of esthetic visual design in educational games", British Journal of Educational Technology 50, 1942-1960, 2019. doi: 10.1111/bjet.12701.

[7] Kovačević, D., Brozović, M., Itrić Ivanda, K.: "Eco-mark on product packaging and its effect on the perception of quality", Journal of Graphic Engineering and Design 10, 17-24, 2019. doi: 10.24867/JGED-2019-2-017.

[8] Lazard, A., Mackert, M.: "User evaluations of design complexity: The impact of visual perceptions for effective online health communication", International Journal of Medical Informatics 83, 726-735, 2014. doi: 10.1016/j.ijmedinf.2014.06.010. 
[9] Lidwell, W., Holden, K., Butler, J.: "Universal principles of design, revised and updated: 125 Ways to enhance usability, influence perception, increase appeal, make better design decisions, and teach through design", (Massachusetts: Rockport Publishers, 2010).

[10] Ling, J., Van Schaik, P.: "The effect of text and background colour on visual search of web pages", Displays 23, 223-230, 2002. doi: 10.1016/S0141-9382(02)00041-0.

[11] Mukai, S., Miyazaki, G.: "Effects of both similarity of the evaluation of impressions, between elements, and font legibility, on aesthetic impression of packaging", International Journal of Affective Engineering 15, 289-293, 2016. doi: 10.5057/ijae.IJAE-D-16-00012.

[12] Ngo, D.C.L., Samsudin, A., Abdullah, R.: "Aesthetic measures for assessing graphic screens", Journal of Information Science and Engineering 16, 97-116, 2001.

[13] Nickel, K., Orth, U.R., Bouzdine-Chameeva, T., Cohen, J., Corsi, A.M., Crouch, R.C., de Marchi, R.: "Designing culturally specific wine packages: The case of visual harmony", $9^{\text {th }}$ Academy of Wine Business Research Conference, Wine Business Research that Matters 2016, (Adelaide, Australia, 2016) pages 342-352.

[14] Nickel, K., Orth, U.R., Kumar, M.: "Designing for the genders: The role of visual harmony", International Journal of Research in Marketing, 2020. doi: 10.1016/j.ijresmar.2020.02.006.

[15] Orth, U.R., Campana, D., Malkewitz, K.: "Formation of Consumer Price Expectation Based on Package Design: Attractive and Quality Routes", The Journal of Marketing Theory and Practice, 18, 23-40, 2010. doi: 10.2753/MTP1069-6679180102.

[16] Pham, B.: "Design for aesthetics: Interactions of design variables and aesthetic properties", Proceeding of $11^{\text {th }}$ Annual Symposium - Electronic Imaging 1999, (SPIE IS\&T/SPIE San Jose, USA, 1999) pages 364-371.

[17] Puhalla, D.: “Design Elements: Form \& Space: A Graphic Style Manual for Understanding Structure and Design", (Rockport Publishers, 2011).

[18] Reimann, M., Zaichkowsky J., Neuhaus C., Bender, T., Weber, B.: "Aesthetic package design: A behavioral, neural, and psychological investigation", Journal of Consumer Psychology 20, 431-441, 2010. doi: 10.1016/j.jcps.2010.06.009.

[19] Silvennoinen, J., Vogel, M., Kujala, S.: "Experiencing visual usability and aesthetics in two mobile application contexts", Journal of Usability Studies 10, 46-62, 2014

[20] Tomko, V., Zaitseva, L.: "Visual design of e-learning systems", Proceedings of $9^{\text {th }}$ International Conference on Advanced Learning Technologies 2009, (ICALT, Latvia, 2009), pages 686-687.

[21] Underwood, R.L., Klein, N.M.: "Packaging as brand communication: Effects of product pictures on consumer responses to the package and brand", Journal of Marketing Theory and Practice 10, 5868, 2002. doi: 10.1080/10696679.2002.11501926.

[22] Van der Laan, L.N., de Ridder, T.D., Viergever, M.A., Smeets, P.A.M.: "Appearance matters: Neural correlates of food choice and packaging aesthetics", Plos One 7, 41738, 2012. doi: 10.1371/journal.pone.0041738.

[23] Vladić, G., Kecman, M., Kasikovic, N., Pal, M., Stancic, M.: "Influence of the shape on the consumers perception of the packaging attributes", Journal of Graphic Engineering and Design, 7, 27-32, 2016.

[24] Westerman, S.J., Sutherland, E.J., Gardner, P.H., Baig, N., Critchley, C., Hickey, C., Mehigan, S., Solway, A., Zervos, Z.: "The design of consumer packaging: Effects of manipulations of shape, orientation, and alignment of graphical forms on consumers' assessments", Food Quality and Preference 27, 8-17, 2013. doi: 10.1016/j.foodqual.2012.05.007.

[25] Williams, B.O., Stimatz, L.R.: "The origins of graphic screen design principles: Theory or rhetoric", International Journal of Instructional Media 32, 181-193, 2005.

[26] Williams, R.: "The non-designer's design book: Design and typographic principles for the visual novice", (Peachpit Press, 2014).

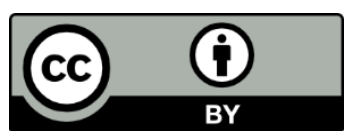

(C) 2020 Authors. Published by the University of Novi Sad, Faculty of Technical Sciences, Department of Graphic Engineering and Design. This article is an open access article distributed under the terms and conditions of the Creative Commons Attribution license 3.0 Serbia (http://creativecommons.org/licenses/by/3.0/rs/). 